\title{
Ochratoxin A in black pepper, white pepper and clove sold in Yaoundé (Cameroon) markets: contamination levels and consumers' practices increasing health risk
}

Evelyne Nguegwouo ${ }^{1 *}$, Lucien Etame Sone ${ }^{1}$, Alex Tchuenchieu' ${ }^{1}$ Hippolyte Mouafo Tene ${ }^{1}$, Emile Mounchigam², Nico Frederic Njayou ${ }^{2}$ and Gabriel Medoua Nama ${ }^{1}$

\begin{abstract}
Background: Spices are widely consumed in Cameroon, but there is no data available concerning their mycotoxin contamination. A cross-sectional study was conducted from February to June 2017 to assess the occurrence of Ochratoxin A (OTA) in black pepper, white pepper and clove sold in three main markets of Yaoundé (the capital of Cameroon), and the health risk that can be associated taking into account consumers' practices during and after purchase.

Results: Data obtained revealed that 10\% of black pepper samples and $40 \%$ of the white pepper samples contained OTA at levels ranging between $1.15-1.91 \mu \mathrm{g} / \mathrm{Kg}$ and $1.81-4.89 \mu \mathrm{g} / \mathrm{Kg}$, respectively. This is below the established European Commission regulated limit of $15 \mathrm{\mu g} / \mathrm{Kg}$ in spices. This toxin was not detected in clove samples. Considering the consumption data collected from our survey, the maximum OTA daily intake was estimated at $0.182 \mathrm{and} 0.699 \mathrm{ng} / \mathrm{kg}$ bw/day for black pepper and white pepper, respectively. This is lower than the EFSA tolerable value of $17 \mathrm{ng} / \mathrm{kg} \mathrm{bw} /$ day. However, it also comes out that $88 \%$ of respondents did not have an idea of mycotoxins. Furthermore, $5-20 \%$ of them do not pay attention to some general quality indicators such as odour, colour and presence of moulds reported by the others when purchasing or storing the three spices, the latter being the most pertinent indicator of the possible presence of mycotoxins. These spices are generally stored at room temperature and for prolonged periods, conditions which are suitable for fungal growth and mycotoxin production.

Conclusion: Although the present study shows limited or no health risk associated to OTA contamination in black pepper, white pepper and clove, it is necessary to enhance consumers' awareness on mycotoxins and their associated impact on health, and to sensitise them on preventive measures to be taken.
\end{abstract}

Keywords: Black pepper, White pepper, Clove, Ochratoxin A, Health risk

\footnotetext{
* Correspondence: nguegwouo@yahoo.fr

${ }^{1}$ Centre for Food and Nutrition Research, IMPM, PO Box 6163, Yaoundé,

Cameroon

Full list of author information is available at the end of the article
} 


\section{Background}

Spices are agricultural products cultured or picked in the wild. They can be seeds (coriander), fruits (pepper and mustard), flowers (saffron and clove), or shoots (skin, roots, and leaves) of several plants that have indigenous or exotic origin and with a strong aroma and taste. They are widely used in daily diet preparations in order to enhance colour, taste, smell, or flavour (Ayres et al., 1980; Anonim 2000; Bulduk 2004). They have also been used as raw materials in pharmaceutical preparations and supplements for dietetic products, especially for "self-medications". Nowadays, due to their preservative and antioxidant properties, spices are widely used for many industrial applications, especially in the food industry (El-Gali 2014).

Even though spices are generally used in small amounts, they represent an important vector of microbial contamination due to the conditions under which they were grown, harvested and processed (Romagnoli et al. 2007; Gnonlonfin et al. 2013).Fungi are the most represented microbial flora isolated from these products. They are able to grow on, and this may subsequently lead to mycotoxin contamination (Kocic-Tanackov et al., 2007). Mycotoxins are a group of secondary metabolites produced by certain fungi that can grow on foodstuffs including spices under certain environmental conditions (Dancea et al. 2004; Arshad and Muhammad, 2012), especially in tropical climates (high ranges of temperature, humidity and rainfall) which are suitable for this toxic metabolites production (Bokhari 2007). Their presence at a certain amount in food can be very harmful for consumers. More than 400 mycotoxins have been identified up to date among which aflatoxins (AFs), fumonisins and ochratoxins are the most studied (Righetti et al. 2016). Ochratoxin A (OTA) or L-phenylalanylcarbonyl-5-chloro-8-hydroxy-3,4dihydro-3-R-methylisocoumarin (Fig. 1) is the most detected mycotoxin in human blood all over the world (Pena et al. 2006). It is mainly produced by fungi belonging to the Aspergillus and Penicillium genera (Amézqueta et al. 2012), principally $A$. ochraceus and $P$. verrucosum (Sibanda et al. 2002). Studies to establish its toxicity showed that this toxin is carcinogenic, teratogenic, genotoxic, immunotoxic, nephrotoxic and neurotoxic (Ringot et al. 2006). The International Agency for Research on Cancer (IARC) of the

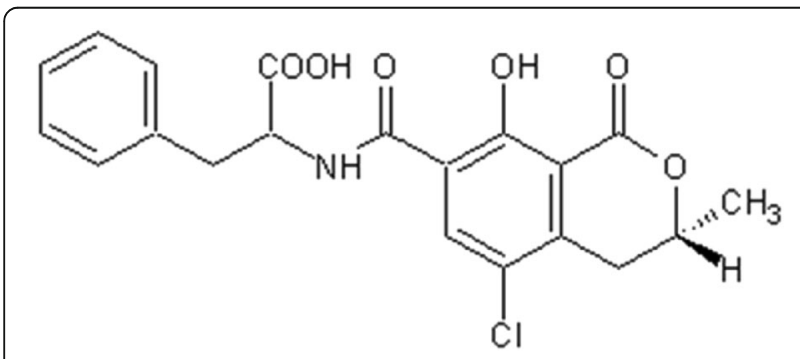

Fig. 1 Chemical structure of Ochratoxin A
World Health Organization (WHO) has classified OTA as toxic for humans (group 2B carcinogen) (IARC 1993). Because of its health impact on humans and animals coupled with its wide distribution in various agricultural commodities, this toxin is considered among the most significant mycotoxins, which are subject to regular inspection.

Taking into consideration the potential health risk associated with OTA, the presence of this mycotoxin in spices has been investigated worldwide. Aziz et al. (1998) reported the presence of OTA in spices collected from various retailers in the city of Cairo (Egypt). Toma and Abdulla (2013) found that OTA was present in spices sold in Iraqi markets in the Erbil city. Salari et al. (2012) also reported the presence of OTA in spices collected from a farm and sun-dried in Iran. Although interest on investigating OTA contamination in spices in other parts of the world has risen, no such studies have been carried out in Cameroon despite the wide use of a plethora of spices in the country. This study aimed at evaluating the occurrence of OTA in some selected spices sold in Yaoundé markets (white pepper, black pepper and clove), and the health risk that can be associated taking into account consumers' practices during and after purchase.

\section{Methods}

Study site

This study was carried out between February and June 2017 in Yaoundé (Centre Region of Cameroon), a multicultural city where black pepper (Piper nigrum L.), white pepper (Piper nigrum L.) and clove (Syzygium aromaticum L.) coming from different regions of the country and from other countries are sold.

\section{Survey}

A total of one-hundred Cameroonians living in Yaoundé were selected to take part in this field survey based on their ease of access. These participants selected were people who usually buy food spices including black pepper, white pepper and clove. A structured questionnaire was administered and it primarily aimed at retrieving information personally from participants that could assist in (i) assessing the frequency and use of these spices; (ii) identifying their quality indicators and the preservation methods used; (iii) evaluating the awareness of the population on risks associated to mycotoxins in spices, and handling measures adopted after purchasing the targeted spices.

\section{Sampling}

Samples (approximately $100 \mathrm{~g}$ each) of black pepper, white pepper and clove were randomly purchased from different sellers at the main markets of Yaoundé (Mokolo, Mfoundi and Mendong markets). The samples collected were taken to the laboratory in condition under which they were sold (sealed plastics in general), 
and dried at $50{ }^{\circ} \mathrm{C}$ for 3 days. Prior to the OTA analysis, the dried samples were ground in a blender (IKA A11 basic; IKA-WerkeGmbH \& Co. KG, Staufen, Germany) to pass through a $500 \mu \mathrm{m}$ sieve.

\section{Ochratoxin A determination}

Ochratoxin A content in each spice was determined using a quantitative ELISA (Enzyme Linked Immounosorbent Assay) kit for Ochratoxin A in Coffee, Cocoa, and Spices (CAT. N ${ }^{\circ}$ 961OCH01COF Qual, HELICA Biosystems, Inc., Santa Ana, CA). The extraction was conducted following the manufacturer's protocol. For each sample, $10 \mathrm{~g}$ of the powder obtained was added to $50 \mathrm{~mL}$ of methanol (LC grade, Merck, Darmstadt, Germany) diluted at $70 \%$. The mixture was then homogenized for 5 min using a vortex (Vortex Genius 3, IKA, Germany) and centrifuged (Eppendorf Centrifuge 5702) at $2000 \mathrm{~g}$ for $10 \mathrm{~min}$. The supernatant obtained was used for the Competitive Direct Enzyme Linked Immunosorbent Assay (CD-ELISA). The OTA content was inversely proportional to the colour intensity established using an automated microplate reader $(\mathrm{EL} \times 800$, BIOTEK, Instruments Inc., Winooski, VT, United States) at $450 \mathrm{~nm}$. OTA content in each sample was calculated based on a calibration curve that was plotted in each experiment using the OTA standard at different concentrations $(0,2,5,10,20$ and $40 \mathrm{ppb}$ ). The correlation coefficients were above 0.99 . The lower and upper limits of quantification of the kit were 1 and $20 \mathrm{ppb}(\mu \mathrm{g} / \mathrm{kg})$, respectively, according to the supplier's information. Samples with toxin values below the limit of quantification (LOQ) were recorded as containing no detectable toxin.

Assessment of the exposure to OTA by the studied spices A deterministic risk analysis was performed as described by Coronel et al. (2011). OTA daily intake (ng OTA/kg bw/ day) was estimated by multiplying the spice OTA concentration $(\mathrm{ng} / \mathrm{g})$ by spice individual consumption data $(\mathrm{g} / \mathrm{kg}$ bw/day) obtained from the survey. Calculations were done assuming an average populations body weight of $60 \mathrm{~kg}$.

\section{Statistical analysis}

The statistical software Sphinx Plus ${ }^{2}$ Lexica was used to generate the questionnaire and analyze the obtained data. The OTA content in the different spices was expressed as mean \pm standard deviation and Statistica10 software of Statsoft used to perform a one-way ANOVA to establish significant differences between the concentration levels obtained $(p \leq 0.05)$. This software was also helpful in generating min, max, mean, P75, P90 and P95 OTA daily intake per spice.

\section{Results}

Socio-demographic and perception study findings

Table 1 presents the descriptive statistics of data collected from the survey. The 100 participants $(15$ men and 85 women) had in common the habit of purchasing the three selected spices. They were from different Cameroonian tribes. Their age was principally in the interval 2135 years old (66\%) and above (25\%). Most of them were single (52\%) and 43\% married. Their academic level ranged from primary level (17\%), high school level (32\%) to university level (47\%). Only $4 \%$ did not have an academic background. Some of them were housekeepers (21\%), students (25\%) and the majority was workers (44\%).

It appears that the three spices are mainly used for cooking purpose as condiments (in large quantities to supplement diets) during food preparations or in low amounts to impart or enhance flavour. For instance, they have been described to be used in the preparation of some traditional meals and beverages, tomatoes and groundnuts sauces, fried eggs etc. The use of spices in folklore medicine has also been described. For example, clove has been described as useful in case of tooth pain, stomach pain, stress, bad breath, cold and to facilitate childbirth. Only a few medicinal properties were reported for black and white peppers. Black pepper is found useful to calm stomach pain by $5 \%$ of the people interviewed, and 1 to $2 \%$ declared that consuming soup, which contained black and white pepper facilitates childbirth.

Concerning the consumption frequency, white pepper is clearly the spice consumed at the highest frequency (at least thrice a week) when compared to the others under study that rather tended to be rarely consumed (at most once a week). An estimation of the average quantities of spices (per food preparation) that can be associated to this consumption frequency shows that quantities below $5 \mathrm{~g}$ are generally used. At quantities above $10 \mathrm{~g}$, white pepper is the most represented.

In terms of quality criteria and preservation methods used, the respondents appreciate the quality of spices during purchase and at storage in homes. Colour and odour were the main attributes of spices taken into account by $48-58 \%$ and $73-77 \%$ of respondents (depending on the spice) respectively, with taste and texture as secondary. The presence of visible moulds and humidity of the spices are also considered during storage at home. It also appears that 5 to $20 \%$ of respondents do not pay attention to these attributes when purchasing or preserving these spices.

The purchased spices are generally consumed throughout if available. The duration of storage at home as reported generally ranges from 0 to 8 weeks and in some cases, can even extend beyond 12 weeks. It is mainly done at room temperature in plastic or glass bottles.

Public awareness about the potential presence of moulds and mycotoxins in spices was also assessed. 
Table 1 Descriptive statistics of data collected from the survey $(n=100)$

\begin{tabular}{|c|c|c|c|c|c|}
\hline Parameters & Incidence $(\%)^{a}$ & Parameters & Incidence $(\%)^{\mathrm{a}}$ & Parameters & Incidence (\%) ${ }^{\mathrm{a}}$ \\
\hline \multicolumn{6}{|c|}{ 1- Socio-demographic variables } \\
\hline Gender & & Age & & Educational level & \\
\hline Male & 15 & $<21$ years & 9 & None & 4 \\
\hline \multirow[t]{2}{*}{ Female } & 85 & $21-35$ years & 66 & Primary & 17 \\
\hline & & $>35$ years & 25 & Secondary & 32 \\
\hline Marital status & & & & University & 47 \\
\hline Single & 52 & Main activity & & & \\
\hline Married & 43 & Housekeepers & 21 & & \\
\hline \multirow[t]{3}{*}{ Divorced } & 5 & Students & 25 & & \\
\hline & & Workers & 44 & & \\
\hline & & other & 10 & & \\
\hline \multicolumn{6}{|c|}{ 2- Use and consumption of spices } \\
\hline Use for food preparation & & Use for folklore medicine & & Average quantity used per meal & \\
\hline As condiments & $91 / 93 / 80$ & Tooth pain & $0 / 0 / 45$ & $<5 \mathrm{~g}$ & 69/62/85 \\
\hline \multirow[t]{2}{*}{ As aroma } & $24 / 33 / 64$ & Childbirth & $2 / 1 / 12$ & $5-10$ & $25 / 24 / 15$ \\
\hline & & Stomach pain & $5 / 0 / 8$ & $10-15$ & $3 / 10 / 0$ \\
\hline \multirow[t]{2}{*}{ Consumption frequency $^{\mathrm{b}}$} & & Stress & $0 / 0 / 4$ & $15-20$ & $1 / 2 / 0$ \\
\hline & & Bad Breath & $0 / 0 / 3$ & $>20$ & $2 / 2 / 0$ \\
\hline Rarely & $63 / 23 / 57$ & Cold & $0 / 0 / 3$ & & \\
\hline Averagely & $24 / 30 / 21$ & & & & \\
\hline Highly & $12 / 47 / 20$ & & & & \\
\hline \multicolumn{6}{|l|}{ 3-Quality indicators } \\
\hline When purchasing & & When storing at home & & & \\
\hline Colour & $48 / 48 / 58$ & Colour & $30 / 26 / 32$ & & \\
\hline Odour & 77/76/73 & Odour & $36 / 37 / 30$ & & \\
\hline Taste & $5 / 6 / 4$ & Presence of moulds & $39 / 32 / 34$ & & \\
\hline \multirow[t]{3}{*}{ None } & $5 / 5 / 7$ & Humidity & $8 / 5 / 4$ & & \\
\hline & & Texture & $6 / 0 / 0$ & & \\
\hline & & None & $13 / 18 / 20$ & & \\
\hline \multicolumn{6}{|l|}{ 4- Storage variables } \\
\hline Storage methods & & Average storage duration & & & \\
\hline Plastics bags & $47 / 52 / 49$ & $<2$ weeks & $27 / 28 / 29$ & & \\
\hline Plastic bottles & $26 / 34 / 40$ & 2-4 weeks & $24 / 26 / 24$ & & \\
\hline \multirow[t]{3}{*}{ Glass bottles } & $38 / 48 / 46$ & $4-8$ weeks & $25 / 29 / 25$ & & \\
\hline & & 8-12 weeks & $10 / 8 / 10$ & & \\
\hline & & $>12$ weeks & $14 / 9 / 12$ & & \\
\hline \multicolumn{6}{|c|}{ 5-Knowledge of fungi and mycotoxins } \\
\hline $\begin{array}{l}\text { Knowledge of fungal } \\
\text { contamination }\end{array}$ & & $\begin{array}{l}\text { Knowledge of mycotoxin } \\
\text { contamination }\end{array}$ & & $\begin{array}{l}\text { Knowledge of health risks associated } \\
\text { with fungal contamination }\end{array}$ & \\
\hline Yes & 94 & Yes & 12 & Yes & 12 \\
\hline No & 6 & No & 88 & No & 88 \\
\hline
\end{tabular}

${ }^{\mathrm{a} B / W / C:} \%$ for Black pepper/White pepper/Clove

${ }^{\mathrm{b}}$ Rarely (At most once a week); Averagely (twice a week); Highly (At least thrice a week) 
Table 2 Ochratoxin A levels in the spices samples

\begin{tabular}{|c|c|c|c|c|c|}
\hline \multirow[t]{2}{*}{ Spice } & \multirow[t]{2}{*}{ Number of samples } & \multirow[t]{2}{*}{ Positive samples } & \multicolumn{3}{|c|}{ OTA level in the positive samples $(\mu \mathrm{g} / \mathrm{Kg})$} \\
\hline & & & Mean $\pm \mathrm{SD}^{*}$ & Min & $\operatorname{Max}$ \\
\hline White pepper & 20 & 8 & $3.30 \pm 1.00^{\mathrm{a}}$ & 1.81 & 4.89 \\
\hline Black pepper & 20 & 2 & $1.53 \pm 0.54^{b}$ & 1.15 & 1.91 \\
\hline Clove & 40 & 0 & - & - & - \\
\hline
\end{tabular}

${ }^{*}$ Mean values not followed by the same letters are significantly different $(p \leq 0.05)$

From this survey, it could be noticed that $94 \%$ of respondents knew about moulds but $88 \%$ of them did not know that mould contamination may imply the presence of mycotoxins. For those who were aware, they reported that they take particular measures such as drying spices to limit mould contamination and to wash them before use.

\section{Ochratoxin A contamination and exposure level}

The Table 2 presents the results obtained from the determination of OTA in the spices samples. Positive samples (OTA content above the $1 \mu \mathrm{g} / \mathrm{kg}$ LOQ) were observed in black and white peppers. With black pepper, only $10 \%$ ( 2 over 20 ) of the samples were positive (mean: $1.53 \pm 0.54 \mu \mathrm{g} / \mathrm{kg}$; max: $1.91 \mu \mathrm{g} / \mathrm{kg}$ ), whereas up to $40 \%$ (8 over 20) of white pepper samples contained OTA at levels (mean: $3.30 \pm 1.00 \mu \mathrm{g} / \mathrm{kg}$; $\max : 4.89 \mu \mathrm{g} / \mathrm{kg}$ ) that were significantly higher than those of black pepper $(p=0.047)$. No presence of OTA was detected in clove samples.

Based on these OTA contamination data and on spices consumption data, the OTA daily intake (min, max, mean and percentiles $75,90,95)$ was calculated for black pepper and white pepper (Table 3). The different values obtained with both spices were very low (almost null), and this, even in our worst-case scenario where an OTA contamination at the highest content observed in each spice were assumed. Although being weak, this toxin daily intake was higher with white pepper than with black pepper. The maximum was estimated at $0.182 \mathrm{ng}$ OTA/kg bw/day for black pepper, and $0.699 \mathrm{ng}$ OTA $/ \mathrm{kg}$ bw/day for white pepper.

\section{Discussion}

Black pepper, white pepper and clove are used worldwide for food and beverages preparation (Babajide et al. 2002; Mann 2011; Sarkar et al. 2015). Many health benefits, including the therapeutic values reported by people we investigated, have been described for clove (Heinrich and Barnes 2004; Jirovetz et al. 2006; Chaieb et al. 2007), and for black pepper and white pepper (Sofowora 1982; Achinewhu et al. 1995; Noumi et al. 1998; Udoh et al. 1999; Mbongue et al. 2005; Ahmad et al. 2012). However, these spices can also be harmful to consumers in case of contamination by mycotoxins such as OTA.

From our analysis, OTA was detected in black and white pepper samples but at levels below the maximum regulatory limit for this toxin in spices set by the European Commission (EC N $\left.{ }^{\circ} 594 / 2012\right)$ which is $15 \mu \mathrm{g} / \mathrm{kg}$. Indeed, growth of ochratoxinogenic moulds in these two spices has previously been reported in literature (Karan et al. 2005; Toma and Abdulla, 2013).The OTA levels obtained from the white pepper analysed in this study are in general below those reported by Jalili et al. (2010) in white pepper from various market outlets in Malaysia $(0.15-13.58 \mu \mathrm{g} / \mathrm{kg})$. As for levels of OTA obtained in black pepper samples in this study, they are also lower than those reported by Jalili (2016) in similar samples imported into Iran $(3.31 \pm 2.69 \mu \mathrm{g} / \mathrm{kg})$ and by Toma and Abdulla (2013) in samples collected from a common market in Erbil city, Iraq $(5.8 \mu \mathrm{g} / \mathrm{kg})$. This suggests a difference in the agricultural or manufacturing (handling, packaging and storage) practices, or the variability of the fungal profile. Besides, as also reported by Jalili (2016),

Table 3 Ochratoxin A daily intake associated to the spices consumption

\begin{tabular}{|c|c|c|c|c|c|c|}
\hline & Min & Max & Mean & P75 & P90 & P95 \\
\hline \multicolumn{7}{|l|}{ Black pepper } \\
\hline Consumption (g/day) & 0.143 & 5.714 & 0.939 & 1.214 & 2.429 & 3.214 \\
\hline OTA daily intake ${ }^{a}$ (ng/kg bw/day) & 0.004 & 0.146 & 0.024 & 0.031 & 0.062 & 0.082 \\
\hline OTA daily intake ${ }^{\mathrm{b}}$ (ng/kg bw/day) & 0.005 & 0.182 & 0.030 & 0.039 & 0.077 & 0.102 \\
\hline \multicolumn{7}{|l|}{ White pepper } \\
\hline Consumption (g/day) & 0.286 & 8.571 & 1.924 & 2.286 & 4.643 & 5.714 \\
\hline OTA daily intake (ng/kg bw/day) & 0.016 & 0.471 & 0.106 & 0.126 & 0.255 & 0.314 \\
\hline OTA daily intake ${ }^{\mathrm{b}}$ (ng/kg bw/day) & 0.023 & 0.699 & 0.157 & 0.186 & 0.378 & 0.466 \\
\hline
\end{tabular}

acalculated with the mean OTA content of positive samples

${ }^{\mathrm{b} C a l c u l a t e d}$ with the highest OTA content of positive samples 
the difference between the environmental conditions (which is an important factor affecting mycotoxin contamination) can also explain the difference between these results. The absence of OTA noticed in clove samples could be related to the antifungal activity of this spice. Mostafa et al. (1990) and Hua et al. (2014) observed the inhibitory effect of clove on fungal growth and OTA production. The absence of OTA in clove has also been reported by Karan et al. (2005) in clove sold at Belgrade, Serbia. Despite having isolated mycotoxinproducing moulds from clove sold in Saudi Arabia, Bokhari (2007) also did not detect the presence of any mycotoxin in this spice.

As observed in this study, white pepper, the spice with the highest OTA content is the most consumed and at the highest frequency. Hopefully, an estimation of the OTA daily intake even with the maximum OTA content detected in positive samples gave values that were far below the Provisional Tolerable Daily Intake (PTDI) value of $17 \mathrm{ng}$ OTA/kg bw/day (EFSA, 2006). Furthermore, the almost null values obtained by evaluating the high percentiles of intake (P75, P90, P95) suggest a limited exposure for high consumers. However, health risk must not be underestimated as the same samples could contain other such significant mycotoxins as aflatoxins and fumonisins that may interact toxicologically with one another and elicit some synergistic and additive effects on consumers (Cheli et al. 2017). To prevent these mycotoxins exposure risk, there is the need to pay attention on some indicators of the presence of mycotoxins when purchasing spices. Among the quality criteria cited by consumers, the presence of moulds is definitely the most pertinent indicator of the possible presence of mycotoxins. The change of colour and odour can be considered as secondary since they are often the results of this fungal growth. Another critical consumers' practice identified which may increase the risk of mycotoxin contamination of spices is during storage. In fact, storage at room temperature in tropical climates and for prolonged periods is suitable for the growth of ochratoxinogenic fungi and subsequent OTA production (Esteban et al. 2004; Pardo et al. 2004; Ribeiro et al. 2006; Passamani et al. 2014). Besides, OTA is a thermally stable compound up to $180{ }^{\circ} \mathrm{C}$ (Raters and Matissek 2008), which is slightly soluble in water (El Khoury et al., 2010). Thus, measures that are applied by some consumers, which consist of drying or washing spices before use, are not likely to reduce OTA content in these spices. There is therefore a need to ensure that handling of spices during storage is done under conditions that limit fungal growth and mycotoxin synthesis.

Many mitigation strategies have been described as useful to reduce mycotoxins in food and feeds (Karlovsky et al. 2016; Cheli et al. 2017; Chilaka et al. 2017). In the case of our studied spices, simple actions like sorting mouldy grains, proper drying, use of appropriate packaging materials and of proper storage methods and facilities may be helpful in limiting contamination. Unfortunately, up to $88 \%$ of our survey respondents indicated they are not aware of the potential presence of mycotoxin in spices. A good starting point should therefore be the enhancement of their knowledge and awareness about what mycotoxins are, the human health risk they pose and preventive measures. Government bodies, private organizations, nongovernmental organizations, media (in electronic or printed forms) can therefore play a key role in attaining this objective (Zain 2011).

\section{Conclusion}

Taking into consideration the maximum OTA content regulated in spices by the European Commission, and the concentrations recovered from the analyzed samples coupled with the amount consumed daily, there appears to be a limited health risk directly associated with OTA contamination in black pepper, white pepper and clove sold in Yaoundé markets. However, efforts should be made to enhance consumers' awareness on mycotoxins and associated impact on health, and to enable consumers adopt mycotoxins preventive measures.

\section{Acknowledgements \\ We thank all those who generously gave their time and agreed to participate in our study survey. We are also grateful to Judith Tsafack, Roger Baleba, Elie Fokou and Patrick Njobeh for their support in this work. \\ Funding \\ Self funded \\ Availability of data and materials \\ All datasets on which the conclusions of the manuscript rely are presented in the paper. \\ Authors' contributions \\ All authors participated in the design and planning of the study; EN, LES, AT, HMT, EM and NFN helped with data collection. These data were analysed by AT and HMT; write-up was done by EN and LES; and all these activities were coordinated by GMN. All authors edited the manuscript and approved its final content.}

Ethics approval and consent to participate Not applicable

Consent for publication

Not applicable

Competing interests

The authors declare that they have no competing interests.

\section{Publisher's Note}

Springer Nature remains neutral with regard to jurisdictional claims in published maps and institutional affiliations.

Author details

${ }^{1}$ Centre for Food and Nutrition Research, IMPM, PO Box 6163, Yaoundé, Cameroon. ${ }^{2}$ Department of Biochemistry, University of Yaoundé I, PO Box 812, Yaoundé, Cameroon. 
Received: 12 September 2017 Accepted: 18 December 2017 Published online: 05 January 2018

\section{References}

Achinewhu SC, Ogbonna CC, Hart AD. Chemical composition of indigenous wild herbs, spices, fruits, nuts and leafy vegetables used as food. Plant Foods Hum Nutr. 1995:48(4):341-8.

Ahmad N, Fazal H, Abbasi BH, Farooq S, Ali M, Khan MA. Biological role of Piper Nigrum L. (black pepper): a review. Asian Pac J Trop Biomed. 2012; 2(3 SUPPL):1-10

Amézqueta S, Schorr-Galindo S, Murillo-Arbizu M, González-Peñas E, López de Cerain A, Guiraud JP. OTA-producing fungi in foodstuffs: A review. Food Control. 2012. p. 259-68.

Anonim. Turkish Food Codex-Spice Paper. Republic of Turkey Ministry of Agriculture and Rural Affairs, Official Gazette, 31.07.2000/24126, Paper No. 2000-16.

Arshad H, Muhammad S. Shafqatullah. Aflatoxin contamination of spices sold in different markets of Peshawar. J Chem Soc Pakistan. 2012;34(5):1052-5.

Ayres Gl, Mund TI, Sondin EW. Microbiology of Food Spices and Condiments. A Series of Books in Food and Nutrition, edn. Schmeigert. 1980. p.249.

Aziz NH, Youssef YA, El-fouly MZ, Moussa LA. Contamination of some common medicinal plant samples and spices by fungi and their mycotoxins. Bot Bull Acad Sin. 1998;39:279-85

Babajide JM, Atanda OO, Idowu MA, Lasekan OO. Microbial and sensory quality of freshly processed and reconstituted "Kununzaki"- a Nigerian millet based beverage. J Food Tech Af. 2002;7:65-7.

Bokhari FM. Spices mycobiota and mycotoxins available in saudi arabia and their abilities to inhibit growth of some toxigenic fungi. Mycobiology. 2007:35(2):47-53.

Bulduk S. Food technology. 2nd ed. Ankara, Turkey: Detay Publishing; 2004.

Chaieb K, Hajlaoui H, Zmantar T, Kahla-Nakbi A Ben, Rouabhia M, Mahdouani K, et al. The chemical composition and biological activity of clove essential oil, Eugenia caryophyllata (Syzigium aromaticum L. Myrtaceae): A short review. Phyther. Res. 2007. p. 501-6.

Cheli F, Pinotti L, Novacco M, Ottoboni M, Tretola M and Dell'Orto V. Mycotoxins in Wheat and Mitigation Measures, Wheat Improvement, Management and Utilization, Ms. Ruth Wanyera (Ed.), InTech. 2017. DOl: https://doi.org/10.5772/ 67240. Available from: https://www.intechopen.com/books/wheatimprovement-management-and-utilization/mycotoxins-in-wheat-andmitigation-measures

Chilaka C, De Boevre M, Atanda O, De Saeger S. The status of Fusarium Mycotoxins in sub-Saharan Africa: a review of emerging trends and post-harvest mitigation strategies towards food control. Toxins (Basel). 2017;9(1):19.

Coronel MB, Marin S, Cano G, Ramos AJ, Sanchis V. Ochratoxin A in Spanish retail ground roasted coffee: occurrence and assessment of the exposure in Catalonia. Food Control. 2011;22(3-4):414-9.

Dancea Z, Baba A, Morar M V., Catoi C, Macri A, Drochner W, et al. Occurrence of fungi with mycotoxic potential in grain of Transylvania and potential hazardous effects in broiler chicken. Mycotoxin Res. 2004. p. 19-23.

EFSA. Opinion of the scientific panel on contaminants in the food chain [CONTAM] related to Ochratoxin A in food. EFSA J. 2006:4(6):1-56.

El Khoury AE, Atoui A, Ochratoxin A. General overview and actual molecular status. Toxins (Basel). 2010;2(4):461-93.

El-Gali ZI. Detection of fungi associated with some spices in original form. Glob J Sci Res. 2014:2(3):83-8.

Esteban A, Abarca ML, Bragulat MR, Cabañes FJ. Effects of temperature and incubation time on production of Ochratoxin A by black aspergilli. Res Microbiol. 2004;155(10):861-6.

Gnonlonfin GJB, Adjovi YC, Tokpo AF, Agbekponou ED, Ameyapoh Y, de Souza C, et al. Mycobiota and identification of aflatoxin gene cluster in marketed spices in West Africa. Food Control. 2013;34(1):115-20.

Heinrich M, Barnes J. Clove, Syzygium aromaticum (L.) Merr. \& L.M. Perry. In, Fundamentals of Pharmacognosy and Phytotherapy. Churchill Livingstone, Edinburgh-London, Great Britain. 2004. p. 275-276.

Hua $H$, Xing F, Selvaraj JN, Wang Y, Zhao Y, Zhou L, et al. Inhibitory effect of essential oils on Aspergillus ochraceus growth and Ochratoxin A production. PLoS One. 2014;9(9).

IARC (International Agency for Research on Cancer). Some naturally occurring substances: food items and constituents, heterocyclic aromatic amines and mycotoxins. IARC Monogr. Eval. Carcinog. Risk Chem. to Humans. 1993. Available from: http://monographs.iarc.fr/ENG/Monographs/vol56/mono56.pdf
Jalili M. Natural occurrence of Ochratoxin A contamination in commercial spices in Tehran. Nutrition and Food Sciences Research. 2016:3(3):25-30.

Jalili M, Jinap S, Radu S. Natural occurrence of Ochratoxin A contamination in commercial black and white pepper products. Mycopathologia. 2010;170(4):251-8.

Jirovetz L, Buchbauer G, Stoilova I, Stoyanova A, Krastanov A, Schmidt E. Chemical composition and antioxidant properties of clove leaf essential oil. J Agric Food Chem. 2006;54(17):6303-7.

Karan DD, Vukojevic JB, Ljaljevic-Grbic M V, Milicevic DR, Jankovic V V. Presence of moulds and mycotoxins in spices. Zb. Matice Srp. Prir. Nauk. 2005;108:77-84.

Karlovsky P, Suman M, Berthiller F, De Meester J, Eisenbrand G, Perrin I, et al. Impact of food processing and detoxification treatments on mycotoxin contamination. Mycotoxin Res. 2016;32(4):179-205.

Kocic-Tanackov SD, Dimi GR, Karali D. Contamination of spices with moulds potential producers of sterigmatocystine. APTEFF. 2007;38:29-35.

Mann A. Biopotency role of culinary spices and herbs and their chemical constituents in health and commonly used spices in Nigerian dishes and snacks. African J Food Sci. 2011;5(3):111-24.

Mbongue FGY, Kantchouing P, Essame OJL, Yewah PM, Dimo T, Lontsi D. Effect of the aqueous extract of dry fruits of Piper Guineense on the reproductive function of adult male rats. Indian J Pharm. 2005:37(1):30-2.

Mostafa EM. Mycoflora and mycotoxins of some spices. M.Sc. Thesis, Botany Dept., Faculty of Science, Assiut University, Egypt. 1990. 60p.

Noumi E, Amvan Zollo PH, Lontsi D. Aphrodisiac plants used in Cameroon. Fitoterapia. 1998:69(2):125-34

Pardo E, Marín S, Sanchis V, Ramos AJ. Prediction of fungal growth and Ochratoxin A production by Aspergillus ochraceus on irradiated barley grain as influenced by temperature and water activity. Int J Food Microbiol. 2004;95(1):79-88.

Passamani FRF, Hernandes T, Lopes NA, Bastos SC, Santiago WD, Cardoso M. Das $\mathrm{G}$, Roberto L. effect of temperature, water activity, and $\mathrm{pH}$ on growth and production of Ochratoxin A by Aspergillus niger and Aspergillus carbonarius from Brazilian grapes. J Food Prot. 2014;77(11):1947-52.

Pena A, Seifrtová M, Lino C, Silveira I, Solich P. Estimation of Ochratoxin A in portuguese population: new data on the occurrence in human urine by high performance liquid chromatography with fluorescence detection. Food Chem Toxicol. 2006:44(9):1449-54.

Raters M, Matissek R. Thermal stability of Aflatoxin B1 and Ochratoxin A. Mycotoxin Res. 2008;24(3):130-4

Ribeiro JMM, Cavaglieri LR, Fraga ME, Direito GM, Dalcero AM, Rosa CAR. Influence of water activity, temperature and time on mycotoxins production on barley rootlets. Lett Appl Microbiol. 2006;42(2):179-84.

Righetti L, Paglia G, Galaverna G, Dall'Asta C. Recent advances and future challenges in modified mycotoxin analysis: why HRMS has become a key instrument in food contaminant research. Toxins (Basel). 2016;8(12):1-22.

Ringot D, Chango A, Schneider YJ, Larondelle Y. Toxicokinetics and toxicodynamics of Ochratoxin A, an update. Chem Biol Interact. 2006;159:18-46.

Romagnoli B, Menna V, Gruppioni N, Bergamini C. Aflatoxins in spices, aromatic herbs, herb-teas and medicinal plants marketed in Italy. Food Control. 2007:18(6):697-701.

Salari R, Najafi MBH, Boroushaki MT, Mortazavi SA, Najafi MF. Assessment of the microbiological quality and mycotoxin contamination of iranian red pepper spice. J Agric Sci Technol. 2012;14(SUPPL.):1511-21.

Sarkar P, Lohith KDH, Dhumal C, Panigrahi SS, Choudhary R. Traditional and ayurvedic foods of Indian origin. J Ethn Foods. 2015;2(3):97-109.

Sibanda L, De Saeger S, Van Peteghem C. Optimization of solid-phase clean-up prior to liquid chromatographic analysis of Ochratoxin A in roasted coffee. J Chromatogr A. 2002;959(1-2):327-30.

Sofowora A. Medicinal plant and traditional medicine in Africa. New-York: John Wiley and Sons; 1982. p. 44

Toma FM, Abdulla NQF. Isolation and identification of fungi from spices and medicinal plants. Res J Environ Earth Sci. 2013;5(3):131-8.

Udoh FV, Lot TY, Braide VB. Effects of extracts of seed and leaf of Piper Guineense on skeletal muscle activity in rat and frog. Phyther Res. 1999;13(2):106-10.

Zain ME. Impact of mycotoxins on humans and animals. J Saudi Chem Soc. 2011:15(2):129-44 